\title{
Design and fabrication of a novel optical sensor for determination of trace amounts of lutetium ion
}

\author{
R. Zare-Dorabei ${ }^{a^{*}}$, M. R. Ganjali ${ }^{b}$, H. R. Rahimi ${ }^{\mathrm{b}}$, H. Farahanic and P. Norouzi ${ }^{\mathrm{b}}$
}

${ }^{a}$ Department of Chemistry, Iran University of Science and Technology, Tehran 16846-13114, Iran

${ }^{b}$ Center of Excellence in Electrochemistry, Faculty of Chemistry, University of Tehran, Tehran, Iran

${ }^{c}$ Environment and Biotechnology Research Division, Research Institute of Petroleum Industry (RIPI), Tehran, Iran

C H R O I C L E A B S T R A C T

Article history:

Received January 26, 2013

Received in Revised form

May 10, 2013

Accepted 28 May 2013

Available online

2 June 2013

Keywords:

Lutetium (Lu)

Optode

Sensor

$N$ '-[(2-hydroxyphenyl)methylene]

benzohydrazide

Triacetylcellulose

\begin{abstract}
In this study, for the first time we report a highly selective and sensitive lutetium ions chemical optical sensor based on immobilization of a asymmetrically S-N Schiff's base, namely N(thien-2-ylmethylene)pyridine-2,6-diamine (TPD) on a triacetylcellulose membrane. This optode exhibits a linear range of $5.0 \times 10^{-7}-1.0 \times 10^{-5} \mathrm{M}$ of the Lu(III) ion concentration with a detection limit of $9.3 \times 10^{-8} \mathrm{M}$ at a wavelength of $336 \mathrm{~nm}$. The influence of responsible factors for improving sensitivity of the sensor was studied and identified. Response time of the newly designed optode was within 20-30 s depending on the Lu(III) ion concentration. Response of the optical sensor is independent of the $\mathrm{pH}$ of the solution in the range of 3.0-9.0. It manifests advantages of fast response time, low detection limit and most significantly, very good selectivity with respect to a number of lanthanide ions. The sensor can readily be regenerated with thiourea solutions and its response was reversible and reproducible. This optode was applied to the determination of $\mathrm{Lu}(\mathrm{III})$ in aqueous and CRM samples.
\end{abstract}

(C) 2013 Growing Science Ltd. All rights reserved.

\section{Introduction}

Lutetium is one of the rare earth elements (REEs) that can be found in houses in equipments such as fluorescent lamps, energy-saving lamps, color televisions and glasses. Use of lutetium is still growing, as it is suitable for catalyzer production and glass polish. In addition, lutetium is dumped in the environment in many different places, mainly from petrol-producing industries. It can also enter the environment when household equipment is thrown away ${ }^{1}$.

The biological properties of the lutetium compounds as well as other lanthanide ions, primarily based on their similarity to calcium, have been the bases for research into potential therapeutic applications of lanthanides since the early part of the twentieth century ${ }^{2-3}$. Lutetium texaphyrin has * Corresponding author. Fax:+98-021-77491204 E-mail addresses: zaredorabei@iust.ac.ir (R.Zare-Dorabei) 
been used as photosensitizer in photodynamic therapy and photoangioplasty ${ }^{4}$. Due to the increasing industrial use of $\mathrm{Lu}$ (III) compounds as well as their enhanced discharge, monitoring of $\mathrm{Lu}$ (III) has been of a recent increasing concern.

Some recent methods for determination of lanthanide ions such as lutetium include inductively coupled plasma mass spectroscopy (ICP-MS) ${ }^{5-6}$, inductively coupled plasma atomic emission spectroscopy (ICP-AES) $)^{7-8}$, flame atomic absorption spectroscopy (FAAS) ${ }^{9}$, activation analysis ${ }^{10}$, photometric determination ${ }^{11}$ and fluorimetry ${ }^{12}$. As a result, design of an inexpensive and simple technique, which can provide the necessary selectivity to determine Lu(III) in the presence of other lanthanides that are very similar to Lu(III) is of great value.

Optical sensors, besides Lu(III) potentiometric ion-selective electrodes which have been already reported $^{13-16}$, can be proper for the $\mathrm{Lu}(\mathrm{III})$ assessment, as they may easily be incorporated into low cost, easy to use kits. Furthermore, they can offer the required selectivity and sensitivity for the environmental monitoring ${ }^{17-22}$. Basic principles and theoretical description of bulk optode membranes, based on the reversible mass analyte transfer from sample in the bulk of the sensing layer have been well elucidated ${ }^{23-25}$.

Beside to other method of analysis of rare earth ions, optical sensors have attracted the attention of many researchers with respect to cost, freedom from electrical interference, safety and the possibility of remote sensing. Also by using optodes, real time analysis can be performed. Sensing material of an optical sensor can be adsorbed on the surface of support materials chemically and physically ${ }^{26}$; chemically immobilized in an appropriate support $^{27-28}$ or physically entrapped in polymeric matrices $^{29-31}$.

In this work, a novel lutetium optical sensor based on immobilization of $\mathrm{N}$-(thien-2-ylmethylene) pyridine-2,6-diamine (TPD) on a triacetylcellulose membrane is introduced. The proposed method offers a more selective and sensitive method for Lu(III) analysis in real samples with lower detection limit in comparison with to the other reported methods.

\section{Experimental}

\subsection{Reagents}

All reagents were prepared from analytical reagent grade chemicals supplied from Merk (Darmstadt, Germany), except $\mathrm{LuCl}_{3}$ which was obtained from Aldrich. The $10^{-2} \mathrm{M}$ lutetium standard stock solution was prepared by dissolving $0.2813 \mathrm{~g}$ of $\mathrm{LuCl}_{3}$ in a $100 \mathrm{~mL}$ volumetric flask and diluting to the mark with distilled water. Universal buffer solutions were prepared from boric acid/citric acid/phosphoric acid solutions ( $0.04 \mathrm{M}$ each). The final $\mathrm{pH}$ was adjusted with the addition of a $0.5 \mathrm{M}$ sodium hydroxide solution.

\subsection{Synthesis of TPD}

The procedure for the preparation of $N$-(thien-2-ylmethylene) pyridine-2,6-diamine (Fig. 1) was as follows. A mixture of thiophene-2-carboxaldehyde $(0.01 \mathrm{~mol}, 1.12 \mathrm{~g}), 2,6$ - diaminopyridine $(0.01$ mol, $1.09 \mathrm{~g})$ and catalytic amount of acetic acid was refluxed for $1 \mathrm{~h}$ in absolute ethanol $(20 \mathrm{ml})$. Then the reaction mixture was then cooled to the room temperature and the yellow precipitate was filtered, washed with ethanol, and dried under the reduced pressure, mp 225-227 ${ }^{\circ} \mathrm{C}, 1.6 \mathrm{~g}$, yield $80 \%$; IR $(\mathrm{KBr})\left(v_{\max } / \mathrm{cm}^{-1}\right): 3340$ and $3186(\mathrm{NH}), 1610,1477,1448,1354,1292,1225,1040,791$, 700. MS, $m / z$ (\%): $203\left(\mathrm{M}^{+}, 5\right), 202$ (15), 183 (4), 128 (24), 109 (100), 82 (55), 55 (15), 45 (14), 39 (18). Anal. Calcd for $\mathrm{C}_{10} \mathrm{H}_{9} \mathrm{~N}_{3} \mathrm{~S}$ (203.27): C, 59.09; H, 4.46; N, 20.67. Found: $\mathrm{C}, 60.1 ; \mathrm{H}, 4.7$; N, 20.4\%. ${ }^{1} \mathrm{H}$ NMR (90 MHz, DMSO- $d_{6}$ solution): $\delta 6.10-6.40\left(4 \mathrm{H}\right.$, br. m, $2 \mathrm{CH}$ and $\left.\mathrm{NH}_{2}\right), 6.95(1 \mathrm{H}$, 
$\mathrm{d}, J=6.1 \mathrm{~Hz}, \mathrm{CH}), 7.10-7.35(4 \mathrm{H}, \mathrm{m}, 4 \mathrm{CH}) ;{ }^{13} \mathrm{C}$ NMR: $\delta 108.24,113.41,121.04,127.69,130.74$, and $135.63(6 \mathrm{CH}), 138.55(\mathrm{C}), 149.88(\mathrm{CH}), 159.09$ and $161.05(2 \mathrm{C})^{13}$.

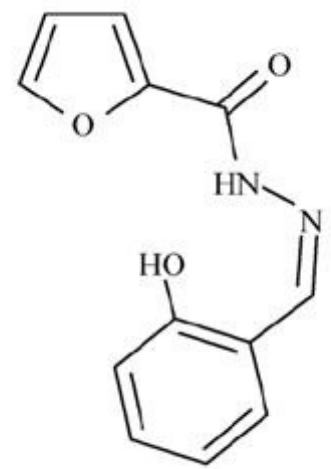

Fig. 1. Structure of N-(thien-2-ylmethylene)pyridine-2,6-diamine (TPD)

\subsection{Apparatus and measurement procedures}

Spectrophotometry measurements were recorded on a PerkinElmer Lambda $2 \mathrm{UV} / \mathrm{vis}$ Spectrophotometer which connected to a Pentium II computer with 1-cm quartz cells. The sensing membrane, which was prepared as mentioned above, was placed and fixed in a disposable plastic cuvette. The length of the film was exactly as the length of the cuvette. Thus, the optode was placed in the cell and could not move during the determinations. All measurements were performed in a batch mode. Optode membrane response to different metal ions was investigated in universal buffer $(0.04 \mathrm{M})$ at $\mathrm{pH}$ value of 4 . Membrane was first exposed to buffer solution and absorbance was measured at $336 \mathrm{~nm}$. Then, the sample solution was added and absorbance at $336 \mathrm{~nm}$ was again measured after $1 \mathrm{~min}$. All results are based on 5 replicate measurements.

\subsection{Preparation of the membrane sensor}

Transparent triacetylcellulose optode were produced from waste photographic film tapes, which were previously treated with commercial sodium hypochlorite for several seconds in order to remove the colored gelatinous layers. The triacetylcellulose film was hydrolyzed in order to de-esterify the acetyl groups and to increase the porosity of the membrane by treating the membrane into $0.10 \mathrm{M}$ $\mathrm{NaOH}$ solution for $24 \mathrm{~h}$. Films $(1 \times 4 \mathrm{~cm})$ were treated with a TPD solution $(0.005 \mathrm{~g})$ in $10 \mathrm{~mL}$ ethylene diamine for $2 \mathrm{~min}$ at ambient temperature. Afterwards, they were washed with water for the removal of ethylene diamine and the loosely trapped indicator (used ligand). Prepared membranes were kept under water, when not in use.

\section{Results and Discussion}

The ionophore TPD, recently have been used as a sensing materials in construction of a selective $\mathrm{Lu}$ (III) membrane sensor. Potantiometric selectivity of the TPD base sensor revealed that that among a number of metal ions tested (including alkali, alkaline metal, heavy and transition metal ions) ${ }^{13}$. Lu (III) has a special tendency to TPD. Thus, in this work TPD was used as a sensing material in construction of a lutetium optical sensor.

\subsection{Spectral characteristics}

Fig. 2(a) and (b) show the absorption spectra in a solution of acetonitrile and immobilized TPD on hydrolyzed cellulose acetate which were obtained after equilibration in buffer solution $(\mathrm{pH}=4)$ containing different concentrations of Lu(III) ions. The spectral characteristic of this optical sensor 
indicate maxima at $336 \mathrm{~nm}$ Fig. 2(b). The spectral change is result of the addition of Lu(III) and complex formation in the optode Fig. 2(b). Also this maxima shifted with increasing $\mathrm{Lu}(\mathrm{III})$ concentration in the optode $336 \mathrm{~nm}$. It is important to note that the absorption spectrum of the immobilized indicator show red shift in comparison to those of their soluble form $315 \mathrm{~nm}$. This observation could be attributed to the fact that the structured conformation of the immobilized indicators is more planar than that of its soluble analogue ${ }^{32}$. As can be seen from Fig. $2 b$ the increase in the absorption band at $336 \mathrm{~nm}$ is more pronounced in the membrane as the Lu(III) concentration increases. For our additional studies, the wavelength of $336 \mathrm{~nm}$ was selected, because of higher selectivity and sensitivity at this wavelength.

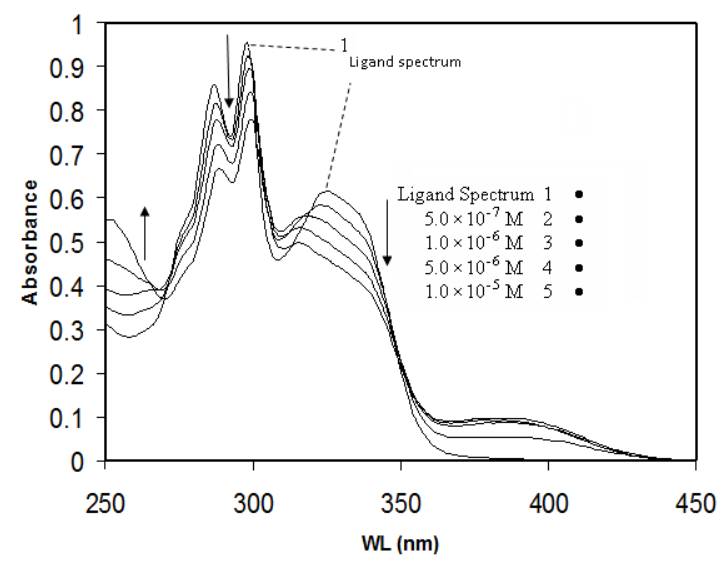

Fig. 2. (a)

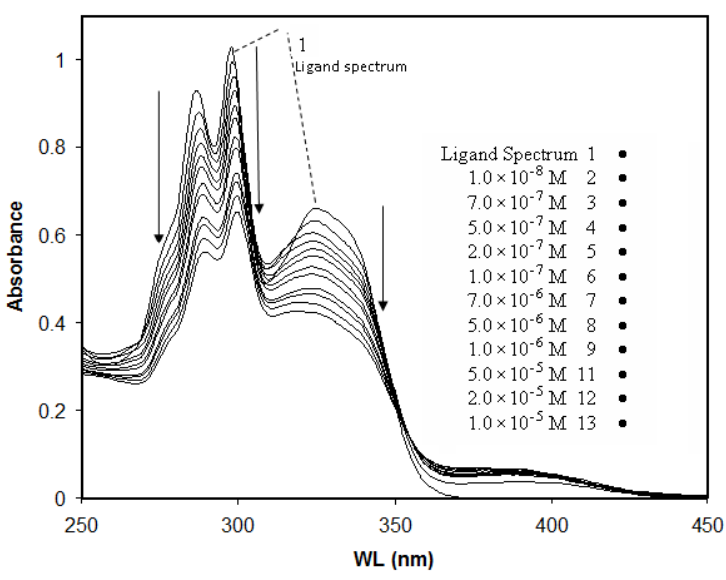

Fig. 2. (a)

Fig. 2. Absorption spectra of solution (a) and optode film (b) response to Absorption spectra of optode film response to $\mathrm{Lu}(\mathrm{III})$ in the range of $5.0 \times 10-7-1 \times 10-5 \mathrm{M}$ at $\mathrm{pH} 4$.

\section{$3.2 \mathrm{pH}$ effect}

$\mathrm{pH}$ influence on the response of the proposed optical sensor was studied in the range of 3.0-9.0 by changing the universal buffer. As it can be noticed in Fig. 3, as the $\mathrm{pH}$ of the solution is increased, the response of the membrane to Lu(III) ions is decreased. The sensor response is almost constant in $\mathrm{pH}$ range of 7-9. A maximum value in the optical sensor response was obtained at $\mathrm{pH}$ value of 4.0. This $\mathrm{pH}$ was selected for our subsequent investigations.

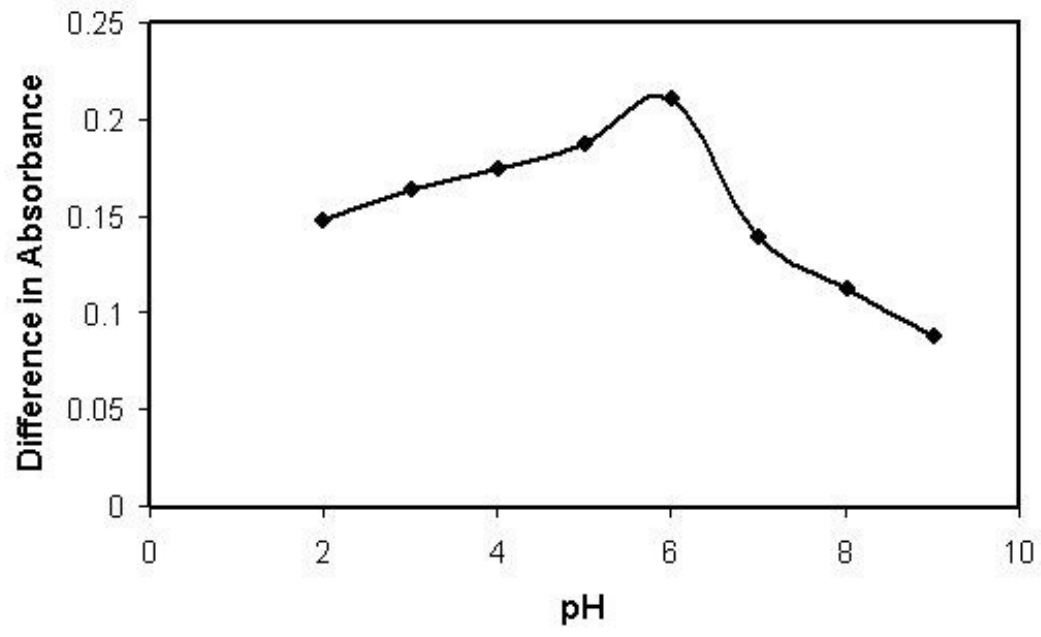

Fig. 3. pH effect on the optode film response 
The observed drift at higher $\mathrm{pH}$ values could be attributed to the hydrolysis of lutetium ions in the solution which decrease the $\mathrm{Lu}$ (III) ions concentration in the solution and inhibits the formation of complex between Lu(III) ions and the TPD. Thus, the optode response decreases. At pH values lower than 3 , the heteroatoms of the ligand in the membrane of the optode are protonated and not able to form complex with $\mathrm{Lu}(\mathrm{III})$ ions in the solution ${ }^{33}$.

\subsection{Response time}

In this research, the optode film was found to reach $95 \%$ of the final signal at 20-30 s, depending on lutetium ions concentration. Fig. 4 shows the time course for the absorption intensity of the membrane at $336 \mathrm{~nm}$. The response time was tested by recording the absorbance change from a pure buffer $(\mathrm{pH}=4)$ to a buffered $\mathrm{Lu}(\mathrm{III})$ solution of $2.5 \times 10^{-6} \mathrm{M}$.

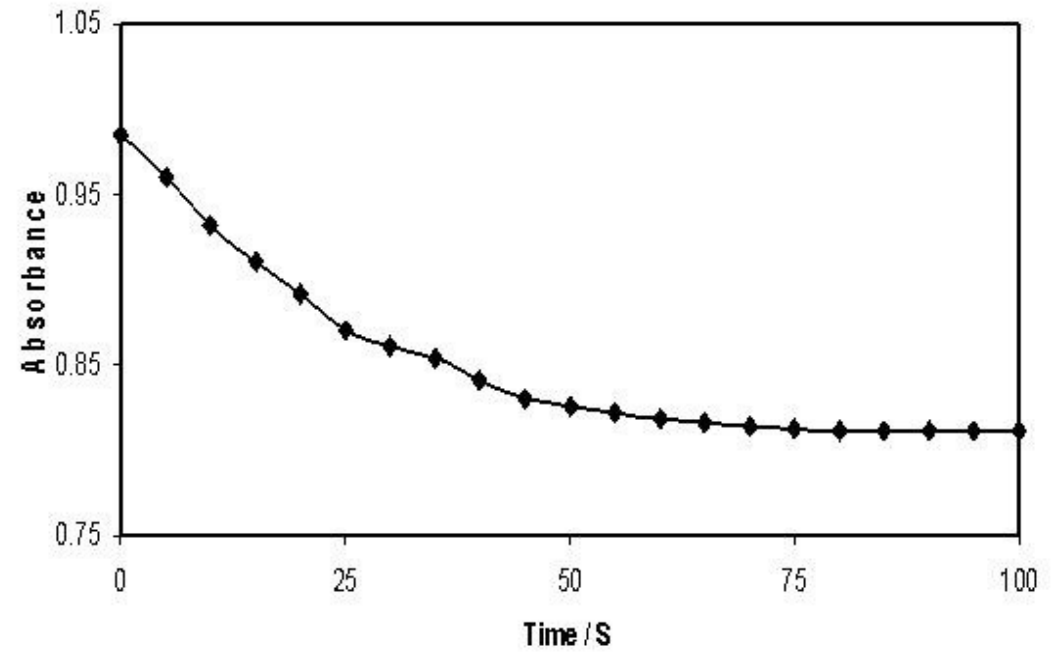

Fig. 4. Response time curve of the film optode at $336 \mathrm{~nm}$ when the film was exposed to $1 \times 10^{-6} \mathrm{M} \mathrm{Lu}$ (III) ion

At high $\mathrm{Lu}(\mathrm{III})$ concentrations, a rapid response was achieved, which resulted in a large change in response. At low $\mathrm{Lu}$ (III) concentrations, a longer response time was produced by the optode film. In general, the response time of the optode film is governed by three processes: (1) film diffusion, (2) complex formation rate between metal ion and ligand and (3) complex dissociation rate ${ }^{34}$. It should be noted that binding of the $\mathrm{Lu}(\mathrm{III})$ ion to ligand TPD is a kind of charge dipole interaction.

\subsection{Dynamic range}

Under the optimum conditions, calibration graphs for $\mathrm{Lu}(\mathrm{III})$ was constructed by plotting absorbance change values as a function of the analyte concentration during a time of $60 \mathrm{~s}$ after the solution contact with sensing phase. The calibration graphs were linear in the range of $5.0 \times 10^{-7}-1.0 \times 10^{-5} \mathrm{M}$ for $\mathrm{Lu}(\mathrm{III})$ ion concentrations. The results are shown in Table 1.

Table 1. Characteristics of calibration graphs for the determination of $\mathrm{Lu}$ (III) ion at $\mathrm{pH}=4$

\begin{tabular}{|c|c|c|c|c|}
\hline Slope $\left(\mathrm{L} \mathrm{mol}^{-1}\right)$ & Intercept & Correlation coefficient & Linear range $(\mathrm{M})$ & Limit of detection (M) \\
\hline 32222 & 0.0132 & 0.9925 & $5.0 \times 10^{-7}-1.0 \times 10^{-5}$ & $9.3 \times 10^{-8}$ \\
\hline
\end{tabular}

The calibration graph is linear up to the $\mathrm{Lu}(\mathrm{III})$ concentration of $1.0 \times 10^{-5} \mathrm{M}$, described by the equation:

$\Delta A b s=32222[\mathrm{Lu}(\mathrm{III})]+0.0132, R^{2}=0.9925$ 
$\triangle A b s$ is the absorbance difference (defined as the difference between the absorbance of the immobilized TPD alone and the absorbance of Lu(III)-TPD complex), [Lu(III)] is the lutetium concentration (M) and $\mathrm{R}^{2}$ is the $\mathrm{R}$-squared value of the calibration curve. Moreover, the detection limit of the sensor film was found to be $9.3 \times 10^{-8} \mathrm{M}$. In this case, detection limit can be defined as the sample concentration yielding a signal which is equal to the blank signal plus three times of its standard deviation.

\subsection{Optode regeneration}

For an optode membrane to perform suitably, absorbance change must be reversible. Tests were conducted with a number of reagents to reverse the absorbance of Lu(III) complex. Complexing agents such as EDTA and sulfosalcylic acid have a partial reverse effect, and prolonged exposure to them have no further improvement in reversibility of the optode. Thiourea $(1.0 \mathrm{M})$ was concluded to be the best reagent, giving a short regeneration time (less than $1 \mathrm{~min}$ ). The on use durability of the sensor phase was obtained by subsequently placing the film in $\mathrm{Lu}(\mathrm{III})$ solutions and regenerating. After regenerating these solutions twice, a drift of about $2.3 \%$ was obtained in response of the sensor film.

\subsection{Reproducibility}

Repeatability and reproducibility of the optical sensors are two important characteristics. Both parameters were studied in this research. To evaluate the discrepancies in the response for successive runs using a single sensor, the repeatability was evaluated by performing 10 determinations with the same $\mathrm{Lu}(\mathrm{III})$ standard solution. The coefficient of variation of sensor response for $8.0 \times 10^{-6} \mathrm{M} \mathrm{Lu}(\mathrm{III})$ was $1.2 \%$. Fig. 5 shows the absorbance changes versus time for the optode membrane. The mean absorbance values with the standard deviation were found to be $0.736 \pm 0.007(n=7,8.0 \mu \mathrm{M} \mathrm{Lu}$ (III) ion) and $0.439 \pm 0.011$ ( $n=7,1.0 \mathrm{M}$ thiourea solution).

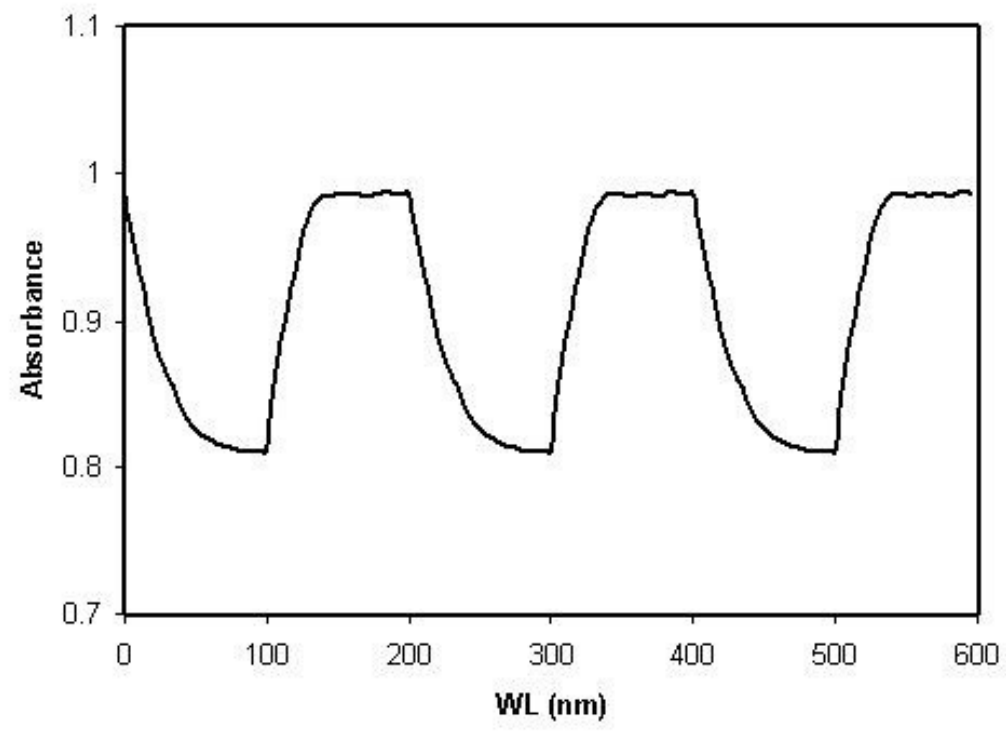

Fig.5. Absorbance variation of the membrane at $336 \mathrm{~nm}$ for repeatedly exposing into $8 \times 10^{-6} \mathrm{M} \mathrm{Lu}$ (III) solution and 1.0 M thiourea solution

For the evaluation of differences in responses of individual sensors, four membranes were prepared from the same mixture. Reproducibility was obtained by determining $8 \times 10^{-6} \mathrm{M}$ lutetium ions (Seven replicate determinations). Coefficient variation of the responses between the membranes was $2.7 \%$. 


\subsection{Lifetime and stability}

The lifetime of the optode film was determined by adding a buffer solution $(\mathrm{pH}=4)$ in to the cuvette, containing the film. The signal was recorded at wavelength of $336 \mathrm{~nm}$ over a period of time (about $10 \mathrm{~h}$ ). No significant indicator loss occurred during that time. When the film was exposed to light, no drift in the signal took place and the optode was found to be stable during the experiment with no indicator leakage. However, the prepared membranes were kept under water, when not in use, to prevent them from drying out. Additionally, stability of film response was investigated over six weeks under ambient conditions, which is indicated that the film was stable over this period.

\subsection{Effect of the foreign ions}

The interference for a number of common species of the absorbance determination of Lu(III) ions was investigated using the prepared sensor. To determine the selectivity of the sensor film, the optode film was tested under lutetium ions concentration of $1 \times 10^{-6} \mathrm{M}$ in the presence of other metal ions. Limit of tolerance was taken as the concentration causing an error of $\pm 5 \%$ in the lutetium ions assay. The results are summarized in Table 2. The surprisingly high selectivity of the optode film for Lu(III) ions over other cations used, most probably arises from the strong tendency of the TPD for formation of stable complex with Lu(III) ions.

Table 2. Influence of the foreign ions on the $\mathrm{Lu}$ (III) determination of $1 \times 10^{-6} \mathrm{M}$

\begin{tabular}{lc}
\hline Interferent & Tolerance ${ }^{\text {a }}$ limit \\
\hline $\mathrm{La}(\mathrm{III}), \mathrm{Sm}(\mathrm{III}), \mathrm{Gd}(\mathrm{III}), \mathrm{Eu}(\mathrm{III}), \mathrm{Tm}(\mathrm{III}), \mathrm{Ca}^{2+}$, & 500 \\
$\mathrm{Ho}(\mathrm{III}), \mathrm{Dy}(\mathrm{III}), \mathrm{Nd}(\mathrm{III}), \mathrm{Ce}(\mathrm{III}), \mathrm{Pb}^{2+}, \mathrm{Na}^{+}, \mathrm{SCN}^{-}$ & 700 \\
$\mathrm{Ni}^{2+}, \mathrm{Cd}^{2+}, \mathrm{Sn}^{2+}, \mathrm{Cu}^{2+}, \mathrm{K}^{+}, \mathrm{Ag}^{+}, \mathrm{Mg}^{2+}, \mathrm{Hg}^{2+}, \mathrm{CO}_{3}{ }^{2-}, \mathrm{NO}_{3}{ }^{-}, \mathrm{Cl}^{-}, \mathrm{Br}^{-}, \mathrm{SO}_{4}{ }^{2-}$ & 1500
\end{tabular}

${ }^{a}$ Maximum ratio of the foreign ions to the cerium ions $\left(1.0 \times 10^{-6} \mathrm{M}\right)$ giving an error of $<5 \%$

\subsection{Recovery tests}

The recovery tests were performed using three different samples (tap, mineral and river water) by using spike method. The test for each sample was carried out in triplicate measurements and the results were given in Table 3. As it is evident from Table 3, lutetium recovery values were between 98 and 103.

Table 3. Results of the recovery test

\begin{tabular}{ccccc}
\hline Sample & Lu (III) Added $(\mu \mathrm{M})$ & Lu (III) Found $(\mu \mathrm{M})$ & R.S.D. \% & Recovery (\%) \\
\hline River Water & 0.00 & ND $^{\mathrm{a}}$ & - & - \\
& 1.00 & 1.03 & 1.80 & 103 \\
Mineral Water & 0.00 & $\mathrm{ND}$ & - & - \\
& 1.00 & 0.98 & 0.94 & 98 \\
\hline
\end{tabular}

\footnotetext{
${ }^{\mathrm{a}}$ Not detected
}

\subsection{Application to synthetic sample and real samples}

The developed lutetium optical sensor device was applied to the detection of lutetium ions in synthetic and river water samples. Table 4 lists the respective resulting data of these applications. The result, derived from seven replicates measurements with the same sensor, was found to be in satisfactory agreement with that determined by Arsenazo (III) method ${ }^{35}$. 
Table 4. Results of the Lu(III) ion concentration measurements in real samples

\begin{tabular}{lcccc}
\hline \multicolumn{1}{c}{ Sample } & $\begin{array}{c}\text { Lu (III) Added } \\
(\mu \mathrm{M})\end{array}$ & $\begin{array}{c}\text { Lu (III) Found } \\
(\mu \mathrm{M}) \\
\text { by Arsenazo } \\
\text { method }\end{array}$ & $\begin{array}{c}\text { Lu (III) Found } \\
(\mu \mathrm{M}) \\
\text { by proposed } \\
\text { method }\end{array}$ & $\begin{array}{c}\text { R.S.D. (\%) } \\
\text { for } \\
\text { proposed } \\
\text { method }(\mathrm{n}=7)\end{array}$ \\
\hline Synthetic sample 1 & 0.00 & $\mathrm{ND}$ & $\mathrm{ND}$ & - \\
Synthetic sample 1 & 1.00 & 1.02 & 0.99 & 1.40 \\
Synthetic sample 2 & 5.00 & 5.06 & 4.94 & 1.20 \\
River Water & 1.00 & 0.98 & 1.01 & 0.97 \\
\hline
\end{tabular}

The characteristics of the proposed lutetium optical sensor were also compared with other methods for determination of lutetium reported in the literature (Table 5). The linear range and detection limit of the proposed optical sensor is acceptable compared to the reported methods; however, literature survey shows that there is no report on an optical sensor membrane with chip reagents for determination of $\mathrm{Lu}(\mathrm{III})$ ions in solutions.

Table 5. Comparison of proposed Lu(III ) optical sensor with other methods for determination of Lutetium

\begin{tabular}{ccccc}
\hline Method & $\mathrm{DL}^{\mathrm{a}}(\mathrm{M})$ & $\mathrm{LR}^{\mathrm{b}}(\mathrm{M})$ & Samples & References \\
\hline ISE & $6.7 \times 10^{-7}$ & $1.0 \times 10^{-6}-1.0 \times 10^{-2}$ & CRM sample & 15 \\
Fluorimetry & $29 \mathrm{ng} / \mathrm{ml}$ & $1.8 \times 10^{-7}-8.8 \times 10^{-6}$ & synthetic sample & 12 \\
Spectrophotometry & $0.114 \mu \mathrm{g} / \mathrm{ml}$ & $0.68-10 \mu \mathrm{g} / \mathrm{ml}$ & synthetic sample & 11 \\
Optical sensor & $9.3 \times 10^{-8}$ & $5.0 \times 10^{-7}-1.0 \times 10^{-5}$ & river water \& CRM & this work \\
\hline
\end{tabular}

Detection limit

${ }^{\mathrm{b}}$ Linear range

The proposed sensor was also applied to Lu(III) determination concentration in the certified reference material (CRM), called Coal and Fuel Ash (FFA 1 Fly Ash). According to Table 6, where the CRM analysis was summarized, the $\mathrm{Lu}(\mathrm{III})$ concentration was $0.658 \mathrm{mg} \mathrm{kg}^{-1}$. Alternatively, the calibration method was employed, illustrating a Lu(III) concentration value of $0.667 \pm 0.3 \mathrm{mg} \mathrm{kg}^{-1}$. These experimental data revealed that the proposed optode performed a trustworthy detection regarding the $\mathrm{Lu}(\mathrm{III})$, despite the presence of other rare earth elements.

Table 6. Results from the Coal and Fuel Ash Analysis (FFA 1 Fly Ash)

\begin{tabular}{|c|c|c|c|c|c|}
\hline \multicolumn{6}{|c|}{ Certified values for $\left(\mathrm{mg} \mathrm{kg}^{-1}\right)$} \\
\hline $\mathrm{Al}$ & 14.87 & Hf & 6.09 & $\mathrm{Sm}$ & 10.9 \\
\hline As & 53.6 & $\mathrm{La}$ & 60.7 & $\mathrm{Sr}$ & 250 \\
\hline $\mathrm{Ba}$ & 835 & $\mathrm{Li}$ & 128 & $\mathrm{Ta}$ & 2.11 \\
\hline $\mathrm{Ce}$ & 120 & $\mathrm{Lu}$ & 0.658 & $\mathrm{~Tb}$ & 1.38 \\
\hline Co & 39.8 & Mn & 1066 & Th & 29.4 \\
\hline $\mathrm{Ca}$ & 156 & $\mathrm{Na}$ & 2.19 & $\mathrm{Tm}$ & 0.705 \\
\hline Cs & 48.2 & $\mathrm{Nd}$ & 56.8 & $\mathrm{U}$ & 15.1 \\
\hline $\mathrm{Cu}$ & 158 & $\mathrm{Ni}$ & 99.0 & $\mathrm{~V}$ & 260 \\
\hline Dy & 9.09 & $\mathrm{P}$ & 725 & W & 10.5 \\
\hline $\mathrm{Er}$ & 4.52 & $\mathrm{~Pb}$ & 369 & $\mathrm{Y}$ & 45 \\
\hline $\mathrm{Eu}$ & 2.39 & $\mathrm{Rb}$ & 185 & $\mathrm{Yb}$ & 4.24 \\
\hline $\mathrm{F}$ & 198 & $\mathrm{Sb}$ & 17.6 & $\mathrm{Zn}$ & 569 \\
\hline $\mathrm{Fe}$ & 4.89 & $\mathrm{Sc}$ & 24.2 & - & - \\
\hline Gd & 10.0 & $\mathrm{Si}$ & 22.48 & - & - \\
\hline
\end{tabular}

\section{Conclusion}

The optical sensor described in this work is easily prepared and provides a simple and inexpensive means for the determination of Lu(III) ions. The optical sensor can be regenerated readily with a solution of thiourea and it has a long lifetime. The optode response was concluded to be reproducible with a good Lu(III) selectivity over other lanthanide ions. Since the optical sensor required no solvent 
extraction, it could compete satisfactorily with the standard optical fibers. This optical sensor was applied to the determination of $\mathrm{Lu}(\mathrm{III})$ in spike and different water samples with good precision and accuracy.

\section{Acknowledgements}

We are grateful for the financial support from the Research Council of Iran University of Science and Technology (IUST), Iran. The author acknowledges financial support from the Iran National Science Foundation (INSF).

\section{References}

1. Bariain C., Matias I. R., Fernandez-Valdivielso C., Arregui F. J., Rodriguez-Mendezb M. L., De Saja J. A. (2003) Optical fiber sensor based on lutetium bisphthalocyanine for the detection of gases using standard telecommunication wavelengths. Sens. Actuators B: Chem. 93, 153-158.

2. Fricker S. P. (2006) Therapeutic application of lanthanides. Chem. Soc. Rev. 35, 524-533.

3. Evans C. H. (1983) Interesting and useful biochemical properties of lanthanides. Trends Biochem. Sci. 8, 445-449.

4. Zhu T. C., Hahn S. M., Kapatkin A. S., Dimofte A., Rodriguez C. E., Vulcan T. G., Glatstein E., His R. A. (2003) In vivo optical properties of normal canine prostate at $732 \mathrm{~nm}$ using motexafin lutetium-mediated photodynamic therapy. Photochem. Photobiol. 77, 81-88.

5. Vio L., Cretier G., Chartier F., Geertsen V., Gourgiotis A., Isnard H., Rocca J. L. (2012) Separation and analysis of lanthanides by isotachophoresis coupled with inductively coupled plasma mass spectrometry. Talanta 99, 586-593.

6. Yang Y. H., Zhang H. F., Chu Z. Y., Xie L. W., Wu F. Y. (2010) Combined chemical separation of $\mathrm{Lu}, \mathrm{Hf}, \mathrm{Rb}, \mathrm{Sr}, \mathrm{Sm}$ and $\mathrm{Nd}$ from a single rock digest and precise and accurate isotope determinations of $\mathrm{Lu}-\mathrm{Hf}, \mathrm{Rb}-\mathrm{Sr}$ and $\mathrm{Sm}-\mathrm{Nd}$ isotope systems using Multi-Collector ICP-MS and TIMS. Int. J. Mass Spectrom. 290, 120-126.

7. Kagaya S., Mizuno T., Tohda K. (2009) Inductively coupled plasma atomic emission spectrometric determination of 27 trace elements in table salts after coprecipitation with indium phosphate. Talanta 79, 512-516.

8. Li Y., Hu B. (2010) Cloud point extraction with/without chelating agent on-line coupled with inductively coupled plasma optical emission spectrometry for the determination of trace rare earth elements in biological. J. Hazard. Mater. 174, 534-540.

9. Biju V. M., Prasada Rao T. (2005) FAAS Determination of Selected Rare Earth Elements Coupled with Multielement Solid Phase Extractive Preconcentration. Chem. Anal. Warsaw 50, 935-944.

10. Pantelica A., Ene A., Georgescu I. I. (2012) Instrumental neutron activation analysis of some fish species from Danube River in Romania. Microchem. J. 103, 142-147.

11. Sanchez F. G., Lopez M. H., Gomez J. C. M. (1987) A graphical derivative approach to the photometric determination of lutetium and praseodymium in mixtures. Talanta 34, 639-644.

12. Yang J., Jie N., Lin C., Wang M., Ma W. (1997) Determination of Lutetium by Fluorimetry, using BPMPHD and CTMAB. Mikrochimica Acta 127, 85-88.

13. Hosseini M., Ganjali M.R., Aboufazeli F., Faridbod F., Goldooz H., Badiei A., Norouzi P. (2013) A selective fluorescent bulk sensor for Lutetium based onhexagonal mesoporous structures. Sens. Actuators B: Chem. DOI: 10.1016/j.snb.2013.04.059.

14. Pourjavid M.R., Razavi T. (2012) 2-Amino-4-(4-aminophenyl)thiazole application as an ionophore in the construction of a Lu(III) selective membrane sensor. Chin. Chem. Lett. 23, 343346.

15. Zamani H. A., Ganjali M. R., Faridbod F. (2011) A lutetium PVC membrane sensor based on (2oxo-1,2--diphenylethylidene)-N-phenylhydrazinecarbothioamide. J. Serb. Chem. Soc. 76, 12951305. 
16. Ganjali M. R., Norouzi P., Atrian A., Faridbod F., Meghdadi S., Giahi M. (2009) Neutral N,N'bis(2-pyridinecarboxamide)-1,2-ethane as sensing material for determination of lutetium(III) ions in biological and environmental samples. Mat. Sci. Eng. C 29, 205-210.

17. Seitz W. R. (1991) Optical ion sensing fiber optic chemical sensors biosensors II. CRC Press, Bocaraton, Florida, pp. 1-19.

18. Castilleja-Rivera W. L., Hinojosa-Reyes L., Guzman-Mar J. L., Hernandez-Ramirez A., RuizRuiz E., Cerda V. (2012) Sensitive determination of chromium (VI) in paint samples using a membrane optode coupled to a multisyringe flow injection system. Talanta 99, 730-736.

19. Noroozifar M., Khorasani Motlagh M., Taheri A., Zare-Dorabei R. (2008) Diphenylthiocarbazone immobilized on the triacetyl cellulose membrane as an optical silver sensor. Turk. J. Chem. 32, 249-257.

20. Zare-Dorabei R., Norouzi P., Ganjali M.R. (2009) Design of a Novel gadolinium optical sensor based on immobilization of (Z)-N_-((pyridine-2-yl) methylene) thiophene-2-carbohydrazide on a triacetylcellulose membrane and its application to the urine samples. Anal. Lett. 42, 190-203.

21. Zare-Dorabei R., Norouzi P., Ganjali M. R. (2009) Design of a novel optical sensor for determination of trace gadolinium. J. Hazard. Mater. 171, 601-605.

22. Ganjali M. R., Zare-Dorabei R., Norouzi P. (2009) Design and construction of a novel optical sensor for determination of trace amounts of dysprosium ion. Sens. Actuators B: Chem. 143, 233238.

23. Seiler K., Simon W. (1992) Theoretical aspects of bulk optode membranes. Anal. Chim. Acta 266, 73-87.

24. Oehme I., Wolfbeis O. S. (1997) Optical Sensors for Determination of Heavy Metal Ions. Mikrochim. Acta 126, 177-189.

25. Narayanaswamy R. (1993) Tutorial review: Optical chemical sensors: Transduction and signal processing. Analyst 118, 317-322.

26. Moreno M. C., Jimenez M., Conde C. P., Camara C. (1990) Analytical performance of an optical $\mathrm{pH}$ sensor for acid-base titration. Anal. Chim. Acta 230, 35-40.

27. Alizadeh K., Parooi R., Hashemi P., Rezaei B., Ganjali M. R. (2011) A new Schiff's base ligand immobilized agarose membrane optical sensor for selective monitoring of mercury ion. J. Hazard. Mater. 186, 1794-1800.

28. Firooz A. R., Ensafi A. A., Kazemifard N., Sharghi H. (2012) A highly sensitive and selective bulk optode based on benzimidazol derivative as an ionophore and ETH5294 for the determination of ultra trace amount of silver ions Talanta 101, 171-176.

29. Sotomayor P. T., Raimundo Jr I. M., Zarbin A. J. G., Rohwedder J. J. R., Alves O. L. (2001) Construction and evaluation of an optical $\mathrm{pH}$ sensor based on polyaniline-porous Vycor glass nanocomposite. Sens. Actuators B: Chem. 74, 157-162.

30. Ling L., Zhao Y., Du J., Xiao D. (2012) An optical sensor for mercuric ion based on immobilization of Rhodamine B derivative in PVC membrane Talanta 91, 65-71.

31. Vukovic J., Avidad M. A., Capitan-Vallvey L. F. (2012) Characterization of disposable optical sensors for heavy metal determination. Talanta 94, 123-132.

32. Jones T. P., Porter M. D. (1988) Optical pH sensor based on the chemical modification of a porous polymer film. Anal. Chem. 60, 404-406.

33. Ganjali M. R., Norouzi P., Daftari A., Faridbod F., Salavati-Niasari M. (2007) Fabrication of a highly selective Eu(III) membrane sensor based on a new S-N hexadentates Schiff's base. Sens. Actuator B: Chem. 120, 673-678.

34. Kuswandi B., Narayanaswamy R. (1999) Characterisation of a $\mathrm{Hg}(\mathrm{II})$ ion optrode based on Nafion-1-(2-thiazolylazo)-2-naphthol composite thin films. J. Environ. Monit. 1, 109-114.

35. Marczenko Z. (1986) Separation and Spectrophotometric Determination of Elements, Elis Horwood Limited, Chichester, pp. 470. 